Persp. Teol. 36 (2004) 15-32

\title{
“É NECESSÁRIO FILOSOFAR NA TEOLOGIA": UNIDADE E DIFERENÇA ENTRE FILOSOFIA E TEOLOGIA EM KARL RAHNER
}

\author{
Manfredo Araújo de Oliveira
}

Resumo:

Partindo da concepção usual entre os católicos da diferença radical entre filosofia e teologia, K. Rahner vai desenvolver uma tese provocativa: a filosofia é um momento interno que ela mesma pressupõe como sua condição de possibilidade. Ele legitima sua tese tanto teologicamente: a partir da relação entre natureza e graça, revelação e teologia, história universal e história especial da salvação e da revelação; quanto filosoficamente: o ser humano é compreensão de si e da totalidade do ser. A teologia, enquanto atividade humana, está subordinada como qualquer conhecimento, às condições necessárias de todo conhecimento humano. Assim, a filosofia enquanto explicitação transcendental das condições de possibilidade do conhecimento teológico constitui um momento interno de seu próprio trabalho.

PALAVRAS-CHAVE: natureza, graça, revelação, filosofia, teologia.

\section{ABSTRACT:}

Parting from the usual conception among Catholics about the difference between philosophy and theology, K. Rahner develops a provocative thesis: philosophy is an interior moment which theology itself presupposes as its condition of possibility. He legitimizes his thesis first theologically: the relation between nature and grace, revelation and theology, universal history and the special history of salvation and revelation; and then, philosophically: the human being is self-comprehension and 
comprehension of the totality of being. Theology, insofar as a human activity, is subordinated as any knowledge to the necessary conditions of all human knowledge. Thus, philosophy, as transcendental expression of the conditions of possibility of theological knowledge, establishes an interior moment of theological activity itself.

KEY WORDS: nature, grace, revelation, philosophy, theology.

\section{A) A unidade e a diferença pensadas a partir da teologia: a filosofia como momento interno da teologia.}

ahner parte da concepção vigente entre os católicos a respeito das duas formas de saber, ou seja, a de uma diferença radical entre ambas, uma vez que se trata de duas realidades originariamente diferentes, e tal diferença é aceita sem questionamentos. Embora sua reflexão não tenha explicitamente como objetivo dar uma resposta aos argumentos apresentados na discussão existente em seu tempo, Rahner pensa no horizonte da polêmica a respeito da "filosofia cristã" e sua relação com a teologia e da tese de K. Barth ${ }^{1}$, com raízes no pensamento de Kierkegaard, de que não há qualquer ponte ou continuidade entre o ser humano e Deus já que o Deus da revelação cristã nada mais é do que o juízo radical sobre o ser humano inclusive sobre seu pensamento a respeito de Deus. Em relação a este pensamento, Deus é o totalmente outro, o desconhecido. A tese provocativa de Rahner vai consistir em afirmar uma unidade fundamental entre filosofia e teologia sem, contudo, negar sua diferença. A tese é: a filosofia é um momento interno da teologia de onde se deriva o imperativo: é necessário filosofar no seio da teologia².

Do ponto de vista teológico, a tese se contrapõe, em primeiro lugar, àquilo que ele denomina o "positivismo dogmático" e o "biblicismo", para ele, os dois perigos que ameaçam atualmente a atividade teológica. O positivismo, de que o biblicismo é apenas uma variante, consiste fundamentalmente em confinar a teologia dogmática à administração, sistematização e, eventualmente, esclarecimento retrospectivo a partir da história dos dogmas, das sentenças do magistério eclesiástico com o auxílio "exclusivo" dos conceitos, modelos de representação, horizontes de questionamento e compreensão dados nelas mesmas, o que para Rahner significa uma limitação indevida

\footnotetext{
${ }^{1}$ A respeito do confronto Rahner x Barth cf. K. P. FISCHER, Der Mensch als Geheimnis: Die Anthropologie Karl Rahners, Freiburg/ Basel/ Wien: Herder, ${ }^{2} 1974$, p. 212ss.

${ }^{2}$ Cf. K. RAHNER, Philosophie und Philosophieren in der Theologie, in Schriften zur Theologie, Einsiedeln: Benziger, vol.VIII, 1967, p. 67. Mais radicalmente ainda L. B. Puntel defende que filosofia e teologia constituem duas perspectivas complementares de uma dimensão teórica (disciplina) idêntica. Cf. L. B. PUNTEL, "A teologia cristã em face da filosofia contemporânea”, Síntese Nova Fase, vol. 28, n. 92 (2001) 359-389.
} 
e em última instância irrealizável da verdadeira tarefa da teologia. A tese rahneriana se entende como uma verdade parcial no contexto de questões teológicas fundamentais, onde ela encontra sua inteligibilidade. Ele a justifica a partir de três questões teológicas básicas:

1) A relação entre Natureza e Graça $a^{3}$ A reflexão rahneriana parte da superação de uma concepção coisal, objetal da graça: a graça não é uma coisa, ela é um dom de Deus, mas, antes de tudo, é o próprio Deus em sua absoluta autodoação (graça não-criada), em gratuidade e proximidade absoluta e radical, ao ser humano que é natureza precisamente enquanto o receptáculo desta doação totalmente indevida uma vez que não é implicada na auto-efetivação do ser humano enquanto tal. Aqui sua obra é Ele mesmo enquanto o comunicado ao ser humano. No ser humano, a graça (graça criada) é um estado determinado de uma pessoa espiritual, portanto, uma determinação, uma forma de ser de um sujeito e por isto enquanto tal formalmente distinta dele e indevida a ele. Assim, a graça só pode ser e ser compreendida enquanto através dela a pessoa, ou seja, a natureza, é, efetiva-se desta forma. A efetivação da graça é necessariamente também efetivação da pessoa natural e, assim, a pessoa é um momento interno na concretude da graça como a potência, é a potência do ato e o ato é ato da potência e ambos se imbricam reciprocamente para poder ser e ser assim. Não pode, portanto, haver graça sem pessoa, pois a graça só existe enquanto afeta uma substancialidade pessoal-espiritual, enquanto ela é seu próprio estado de divinização.

Questão fundamental aqui é a compreensão de que a divinização do ser humano é a realização absoluta e gratuita de um ente que, em virtude de sua espiritualidade e transcendência ao ser enquanto tal, não pode ser definido e determinado da mesma forma que os entes infra-humanos. A característica específica destes entes consiste em sua limitação a um campo determinado da realidade. Por esta razão, eles não poderiam ser elevados a uma realização sobrenatural, porque tal elevação romperia com sua essência enquanto limitação essencial. Em contraposição, a "definição" do espírito criado, sua especificidade constitucional, é sua "abertura" ao ser enquanto tal: ele é criatura espiritual enquanto é abertura à plenitude da realidade, à totalidade do ser, à realidade enquanto tal. O horizonte supremo de todos os seus atos é o ser, que não é um objeto entre outros, mas o horizonte em que se situam todos os objetos singulares de nosso pensamento e de nossa liberdade.

${ }^{3}$ Cf. K. RAHNER, Natur und Gnade, op. cit., vol. IV, 51967, pp. 209-236. G. BAUDLER, "Göttliche Gnade und menschliches Leben: Religionspädagogische Aspekte der Offenbarungs- und Gnadentheologie Karl Rahners", H. VORGRIMLER (ed.), Wagnis Theologie. Erfahrungen mit der Theologie Karl Rahners, Freiburg / Basel / Wien: Herder, 1979, pp. 35-50. 
Assim, não pode haver espírito sem transcendência aberta a esta elevação sobrenatural ${ }^{4}$, embora o espírito tenha sentido mesmo que não seja sobrenaturalmente agraciado, pois isto não constitui uma exigência de sua essência. O ser humano só é, então, conhecido em sua essência indefinível, quando ele é compreendido como potentia oboedientialis para a vida divina e é isto que constitui sua essência. Por esta razão, a graça pressupõe necessariamente a realidade desta pessoa que, enquanto ser espiritual, é radicalmente aberta e orientada para Deus como condição de sua própria possibilidade e a assume em si como momento de seu próprio ser efetivo. O paradoxo que constitui o ser humano é que ele tem que esperar sua realização absoluta enquanto graça, mas porque é assim, tem que contar a partir de si mesmo com a possibilidade da não efetivação desta realização absoluta.

Dentro do horizonte da problemática teológica da relação entre natureza e graça se situa o problema da relação entre filosofia e teologia: a graça, enquanto autocomunicação absoluta de Deus, para poder ser, tem que pressupor um parceiro, como sua condição de possibilidade, a quem ela é indevida, isto é, que pode ser pensado sem esta comunicação, mas sem o qual não poderia haver comunicação, ou seja, a revelação pressupõe o outro de si mesma "enquanto outro" para que ela mesma possa ser. O ser espiritual é a condição de possibilidade que a própria revelação pressupõe para si mesma e com isto a põe livremente para que ela possa ser o que é: graça enquanto autocomunicação pessoal e livre de Deus. Teologicamente, Rahner ${ }^{5}$ exprime isto dizendo que a revelação, enquanto gnosis do filho gratuitamente adotado a partir da graça, pressupõe o escravo como sua condição de possibilidade. Deus criou o escravo para fazer dele seu filho.

Na mesma perspectiva se deve afirmar: Deus só quis a verdade da filosofia, porque queria para nós a verdade de sua própria auto-revelação, porque queria para nós a verdade absoluta, bem-aventurada, que é Ele mesmo. Numa palavra, a revelação pressupõe a filosofia enquanto diferente dela e livre enquanto espaço de sua própria possibilidade, porque só ao ser que compreende a si mesmo e dispõe autonomamente sobre si mesmo, o ser espiritual finito, pode dirigir-se a automanifestação de Deus em revelação pessoal enquanto o ato de seu amor livre. A autonomia do ser espiritual enquanto "natureza" é a condição de possibilidade daquela "obediência" através da qual somente a revelação pode ser aceita como ela tem

\footnotetext{
4 Já no "Hörer des Wortes" (Ouvinte da palavra), uma obra do jovem Rahner, é tarefa essencial da filosofia entender o ser humano como alguém que é preparado para a recepção da revelação e, neste sentido, filosofia é praeparatio evangelii. Enquanto tal, a filosofia se suprime a si mesma, quando ela levanta a pretensão de ser a fundamentação existencial última da existência humana. Cf. K. RAHNER, Hörer des Wortes: Zur Grundlegung der Religionsphilosophie. Neu bearbeitet von. J. B. Metz, München: Kösel, 1963, p. 38.
}

${ }^{5}$ Cf. K. RAHNER, op. cit., vol. VI, p. 96. 
que ser aceita, isto é, na aceitação livre da graça. Numa palavra, a revelação e sua teologia exigem a partir de si mesmas uma filosofia enquanto ciência autônoma assim como a realidade da redenção pressupõe a realidade autônoma da criação enquanto sua condição de possibilidade. Assim, a teologia da revelação enquanto ciência tem como seu fundamento transcendental de possibilidade o horizonte transcendental ilimitado do espírito humano a partir de onde todas as afirmações sobre Deus valem e têm que ser compreendidas de tal modo que a reflexão sobre o ouvinte da palavra é um momento interno dela mesma ${ }^{6}$. Esta filosofia pode ser dita cristã tanto porque compreende o ser humano como essencialmente orientado para Deus e aberto a sua auto-revelação como porque já atematicamente marcada pela graça de Deus que é co-extensiva a toda a vida humana.

2) Relação entre Revelação e Teologia. Para Rahner, aqui também não há lugar para uma dicotomia plena, pois a revelação, enquanto aceita na fé, já é necessariamente também teologia, certamente uma teologia rudimentar, mas de qualquer modo teologia. Isto porque a revelação ocorre na história e na palavra humana, portanto, inserida no horizonte de compreensão do ser humano e por isto subordinada às estruturas aprióricas de seu conhecimento ${ }^{8}$. Assim, a palavra é ouvida por um homem que já possui conhecimentos anteriores a ela. Ora, o ouvir uma mensagem por parte de alguém que já tem conhecimentos só pode acontecer na unidade deste sujeito, portanto, consciente ou não, em confrontação com o saber anterior o que significa dizer que o ouvir efetiva-se através da mediação do horizonte e das categorias já possuídas neste saber anterior independentemente da consciência que se tenha disto ou não. Numa palavra, ele já é uma produção ativa do pensamento, portanto, teologia, uma vez que teologia é sempre ciência da fé cristã, isto é, uma reflexão do crente e da Igreja enquanto seu corpo", realizada sob a luz da fé, um conhecimento "engajado" da automanifestação salvífica do Deus trinitário em Cristo, portanto, conhecimento do ato e do conteúdo da fé cristã e eclesial. A teologia enquanto reflexão metodicamente dirigida sobre a revelação de Deus dada na fé é possível e necessária, porque a revelação de Deus na palavra já possui em si um saber de conceitos e sentenças enquanto seu momento ${ }^{10}$ que enquanto momento da fé e de sua pregação responsável a outros tende a um desdobramento, a uma reflexão e a uma confrontação com outros saberes.

\footnotetext{
${ }^{6}$ Cf. K. RAHNER, op. cit., vol. VIII, p. 51. P. EICHER, Die anthropologische Wende: Karls Rahner philosophischer Weg vom Wesen des Menschen zur personalen Existenz, Freiburg/Schweiz: Universitätsverlag, 1970, p. 91ss.

${ }^{7}$ Cf. G. MUSCHALEK, "Die Annahme des einen Menschen: Gedanken zur Mitte der Glaubenstheologie Karl Rahners”, in H. VORGRIMLER (ed.), op. cit., pp. 113-122.

${ }^{8}$ Cf. K. RAHNER, Überlegungen zur Methode der Thelogie, op. cit., vol. IX, 1970, p. 103.

${ }^{9}$ Cf. K. RAHNER, "Dogmatik" in Sacramentum Mundi. Theologisches Lexikon für die Praxis, Freiburg / Basel / Wien: Herder, vol. I, 1967, p. 917.

${ }^{10}$ Cf. K. RAHNER, “Theologie” in: Sacramentum Mundi, op. cit.,vol. 4, p. 862.
} 
Assim, uma tal teologia, enquanto elemento necessário e ineliminável do ouvir da revelação, implica necessariamente filosofia, não ainda em sentido técnico de um saber metodicamente articulado, mas enquanto autocompreensão transcendental e histórica do ser humano, ou seja, implica filosofia na medida em que o ser humano é o ser "onto-lógico", o ser que em qualquer juízo sobre um objeto sempre compreende a si mesmo e seu mundo a partir do horizonte de uma transcendência sem limites, embora de uma forma ainda atemática, ou seja, ele sempre compreende sua essência metafísica: espírito, em transcendência e liberdade ${ }^{11}$, e só existe no mundo enquanto o ente que compreende o ser. A filosofia, no sentido técnico, nada mais é para Rahner, do que uma exposição e articulação, metodicamente exata, refletida e controlada, desta autocompreensão originária do ser humano, nunca plenamente explicitável na esfera do saber consciente. Teologicamente isto implica dizer que a revelação pressupõe este conhecimento filosófico enquanto outro como sua condição de possibilidade ${ }^{12}$. Só assim, segundo Rahner, se pode evitar o dilema em que a revelação ou cai em dependência de um conhecimento heterogêneo a ela ou simplesmente tem que ser independente da filosofia.

Daqui a conclusão: não existe anúncio da revelação sem teologia e não pode haver teologia sem filosofia. Uma teologia não filosófica seria uma teologia ruim ${ }^{13}$, portanto, é necessário filosofar na teologia e isto acontece quando o ser humano confronta radicalmente a mensagem da fé com sua compreensão de si mesmo e do mundo, transcendental e histórica, uma vez que só assim esta mensagem pode falar soteriologicamente ao ser

${ }^{11}$ Cf. K. RAHNER, Natur und Gnade, op. cit., p. 230

${ }^{12}$ Rahner tem consciência da situação existencial do teólogo no mundo de hoje em que há um pluralismo de posturas filosóficas e científicas, que constituem um desafio à teologia, com que ele tem de se confrontar, embora estas posturas não sejam adequadamente sintetizáveis nem através de si mesmas nem através da teologia, e o teólogo individualmente experimente a impossibilidade de poder conhecer com seriedade todas estas propostas. Estamos assim muito longe da situação de trinta anos atrás em que a teologia católica era literalmente um sistema fechado, seguro em si mesmo, e a filosofia moderna e a teologia evangélica eram consideradas inimigos externos a combater. $\mathrm{O}$ cenário intelectual do mundo contemporâneo é radicalmente diferente e ameaça o sistema teológico a partir de dentro. Não existe mais uma linguagem filosófica e teológica comum que pudesse valer como pressuposto do trabalho e do diálogo teológicos. No entanto, apesar desta enorme dificuldade teórica, o teólogo não pode renunciar à sua tarefa, e ela leva hoje inevitavelmente à formação de "muitas teologias", o que levanta problemas inteiramente novos ao magistério eclesiástico. Cf. K. RAHNER, op. cit, vol. VIII, p. 68ss; pp. 73-81; op. cit., vol. IX, 1970, p. 83ss; p. 111ss. A respeito da problemática posta na situação contemporânea e a solução numa direção diferente cf. J.B. LIBÂNIO, "Desafios da Pós-Modernidade à teologia fundamental", in J. TRASFERETTI / P.S.L. GONÇALVES (eds.), Teologia na Pós-Modernidade: Abordagens epistemológica, sistemática e teórico-prática, São Paulo: Paulinas, 2003, pp. 143-171.

${ }^{13}$ Cf. K. RAHNER, op. cit., vol. VI, p. 101. M. CABADA-CASTRO, "Ort und Bedeutung des philosophischen Gottesbegriffs im Denken Karl Rahners", in H. VORGRIMLER (ed.), op. cit., p. 160ss. 
humano integralmente em seu ser pessoal livre. Isto continua válido mesmo que seja verdade que o parceiro decisivo da teologia no futuro cada vez mais seja menos a filosofia no sentido tradicional, mas as ciências nãofilosóficas ${ }^{14}$, ciências naturais, históricas e sociais, que existem pluralisticamente, hoje, e que trazem em si uma compreensão da existência humana nelas fundada e por elas indiretamente exigida que, portanto, coconstituem a autocompreensão do ser humano. Rahner ${ }^{15}$ pergunta-se, contudo, se esta autocompreensão do ser humano, que é momento interno da teologia e sua condição de possibilidade, é dada ao teólogo somente através da palavra como se pressupõe ou se não, também hoje, através de fontes de conhecimento que substituem a palavra, como, por exemplo, a "imagem" e a "ação" da razão prática, as quais nunca podem ser adequadamente transmitidas através das produções da razão teórica. O teólogo hoje não dispõe mais daquele espaço comum que fazia sua vinculação com seus colegas, mas se encontra só e isolado diante desta multiplicidade de saberes ${ }^{16}$. Para Rahner ${ }^{17}$ este pluralismo, também no seio da própria teologia, significa a expressão de uma situação gnosiologicamente concupiscente do cristão individual, dos teólogos e da consciência teológica da Igreja num mundo fundamentalmente pluralista ${ }^{18}$. Pela primeira vez em sua história, a teologia não só é condicionada por horizontes históricos de compreensão, mas tem também consciência desta condicionalidade e de sua inevitabilidade.

3) Diferença entre a história universal e a história especial, lingüísticoconceitual, da salvação e da revelação.

A relação mais profunda entre filosofia e teologia pode ser pensada a partir da distinção entre a história universal da salvação e da revelação e sua história especial. Quem crê na vontade salvífica universal de Deus em relação a toda a humanidade, não pode negar seriamente que a história da salvação é co-extensiva à toda a história pessoal da humanidade o que significa dizer que a história salvífica universal é uma história universal da revelação de Deus que é co-extensiva à história da humanidade, respectivamente à história das religiões. Por esta razão, é impossível conceber um mundo qualquer sem referência à graça ou marcado pela maldição definitiva: todo e qualquer homem é vocacionado a partilhar da própria vida de

${ }^{14}$ Cf. K. RAHNER, "Der Pluralismus in der Theologie und die Einheit des Bekenntnisses in der Kirche", in op.cit., vol. IX, p. 13ss.

${ }^{15}$ Cf. K. RAHNER, , op. cit., vol. IX, p. 85.

${ }^{16} \mathrm{O}$ que não diminui a necessidade de uma justificação da fé. Isto, nesta enorme complexidade de problemas, ele só poderá realizar através do que Rahner denomina "métodos indiretos". Cf. a respeito: K. RAHNER, op. cit., vol. IX, pp. 86-95.

${ }^{17}$ Cf. K. RAHNER, op. cit., vol. IX, p. 21.

${ }^{18}$ Cf. K. RAHNER, "Über den Dialog in der pluralistischen Gesellschaft", in: op. cit., vol. VI, pp. 46-58. 
Deus, é destinatário da autocomunicação e auto-revelação de Deus. Nenhum ser humano, portanto, está fora da benevolência divina. Por esta razão, o último mistério do ser humano é de natureza sobrenatural, embora uma reflexão posterior não seja capaz de distinguir claramente a transcendência ao ser enquanto tal, a abertura natural à totalidade do ser que caracteriza o espírito humano e a transcendência sobrenatural do espírito, aberta e sustentada pela graça, em todos os atos sobrenaturalmente elevados, ao Deus da vida eterna ${ }^{19}$, ao Deus trinitário.

Esta revelação universal não ocorre, no entanto, no saber explícito de objetos, mas através de uma mudança do horizonte atemático da situacionalidade fundamental do ser espiritual-pessoal. A conseqüência desta situacionalidade sobrenatural do ser humano é a presença do que Rahner chama de "existencial sobrenatural", que ocorre aí onde o ser humano vive na graça, quer ele tenha consciência disto ou não. Daqui se segue que a ordem atual da humanidade é a ordem da salvação e diz respeito universalmente a todos os seres humanos em todos os tempos. Ora, nesta ordem, a autocompreensão do ser do homem e de toda a realidade, que chamamos "filosofia", é "pura" no sentido de que ela não recebe conteúdos ou normas da revelação temática, pública, articulada socialmente e com isto eclesial. Não é pura, porém, no sentido de que o "horizonte atemático de compreensão do ser humano e do mundo" a partir de que ela vive, só contivesse elementos provenientes da essência natural do homem. Por isto, quando a revelação explicitamente cristã pressupõe e põe a filosofia como um momento interior a si, mas metodicamente independente como sua condição de possibilidade, isto não ocorre como posição de uma possibilidade pura, porque a filosofia já é, de certa forma, cristã, uma vez que, saiba ela disto ou não, é iluminada pela luz da graça que Deus não recusa a qualquer ser humano. Em cada filosofia já se faz inevitável e atematicamente teologia, porque não depende do ser humano ser envolvido ou não pela graça de Deus. Nós cristãos é que somos muito cegos, porque não somos capazes de ver este cristianismo oculto na história do ser humano, da religião e da filosofia.

\section{B) A unidade e a diferença pensadas a partir da filosofia: a filosofia enquanto pressuposto transcendental da atividade teológica.}

A questão fundamental da filosofia, como ela se explicitou na modernidade no pensamento de Kant, é a pergunta pela possibilidade da metafísica. Pôr uma pergunta metafísica significa para Rahner articulá-la enquanto "pergunta pelo ser" do ente enquanto tal, enquanto pergunta pelo sentido do

${ }^{19}$ Cf. K. RAHNER, op. cit., vol. IV, p. 225. 
$\operatorname{ser}^{20,}$ de tal modo que toda pergunta metafísica tem que abranger de certo modo o todo da metafísica uma vez que ela tem a ver com a totalidade do $\operatorname{ser}^{21}$. "Neste sentido, a pergunta metafísica é aquela 'pergunta universal', que contém em si todas as perguntas, pois perguntando pela realidade enquanto tal, insere, de certo modo, tudo nesta pergunta fundamental ${ }^{22}$ ". A pergunta por sua possibilidade pode encontrar uma resposta na medida em que se mostra que em todo conhecimento da experiência já é sempre "co-posta" uma compreensão metafísica do ser. Precisamente aqui está para Rahner o núcleo duro da filosofia: a demonstração de que o ser finito, temporal e histórico, permanentemente marcado por ameaças e obscuridades, já se situa sempre na esfera da metafísica, portanto, é em última instância dinamicamente orientado teórica e praticamente ao absoluto. Esta compreensão metafísica do ser é condição de possibilidade da experiência do ser humano no mundo e, ao mesmo tempo, abre o espaço para uma compreensão metafísica do ser humano e de sua abertura a uma possível revelação de Deus.

Na linha aberta por J. Maréchal23, de diálogo com a filosofia transcendental da modernidade e com a ontologia fundamental de M. Heidegger ${ }^{24}$, Rahner articula o que poderíamos chamar uma "metafísica transcendentalmente mediada", isto é, uma metafísica legitimada por uma fundamentação última no sentido de que ela se legitima por uma "reflexão transcendental", já que para ele toda metafísica verdadeira, toda filosofia que merece este nome, tem que trabalhar transcendentalmente, isto é, legitimar-se através de uma reflexão sobre os pressupostos necessários do pensar e do agir implicitamente presentes no sujeito, o que significa dizer que a filosofia não pode trabalhar a partir de pressupostos não demonstrados e que, portanto, a pergunta pela possibilidade da metafísica é uma pergunta da própria metafísica. Numa palavra, um questionamento transcendental está presente, segundo Rahner, independentemente do campo de conhecimento em que ele emerge, quando e na medida em que se pergunta pelas condições de possibilidade no sujeito cognoscente do conhecimento de um determinado objeto ${ }^{25}$.

${ }^{20}$ Cf. K. RAHNER, Hörer des Wortes, op. cit., p. 49.

${ }^{21}$ Cf. K. RAHNER, Hörer des Wortes, op. cit., p. 48.

${ }^{22}$ Cf. M.A. DE OLIVEIRA, Filosofia Transcendental e Religião: Ensaio sobre a Filosofia da Religião em Karl Rahner, São Paulo: Loyola, 1984, p. 125.

${ }^{23}$ Cf. J. MARÉCHAL, Le point de départ de la métaphysique: Leçons sur le développement historique et théorique du problème de la conaissance. Cahiers I-V, Brussel / Paris: Museum Lessianum, 1944-1949. H. MUCK, Transzendentalphilosophie und Metaphysik: Studie über Tendenzen in der heutigen Grundlagenproblematik, Mainz: MathiasGrünewald-Verlag, 1966.

${ }^{24}$ A respeito das ligações do pensamento de Rahner com Heidegger cf. L. DÜMPELMANN, "Überlegungen zur phänomenologischen und transzendentalen Fragestellung beim frühen Heidegger", in H. VORGRIMLER (ed.), op. cit., pp. 176-188. M.A. DE OLIVEIRA, Filosofia Transcendental e Religião, op. cit., p. 87ss.

${ }^{25}$ Cf. L. PUNTEL, 'Zu den Begriffen ,transzendental' und ,kategorial' bei Karl Rahner", in H. VORGRIMLER (ed.), op. cit. , pp. 189-198. 
Está em jogo no conhecimento não somente o conhecido, mas também o cognoscente, o conhecimento depende não só do objeto, mas também da estrutura essencial do sujeito que conhece, e o conhecimento de si mesmo do sujeito cognoscente é sempre também um conhecimento da estrutura metafísica do próprio objeto. Esta afirmação será fundamentada mais tarde a partir da própria tese inicial da metafísica rahneriana: ser e conhecer constituem uma identidade originária. "A metafísica é, assim, necessariamente, 'onto-logia', análise do ser, que é essencialmente lógica" ${ }^{26} \ldots$. Se é assim, então a pergunta pelo ser implica uma pergunta pelo conhecer, de tal modo que a crítica do conhecimento não é uma disciplina prévia ao conhecimento metafísico, mas constitui um momento interno dele. Portanto, filosofia transcendental e metafísica se identificam, assim que para Rahner a filosofia transcendental constitui a verdadeira forma da filosofia, embora só se tenha tornado reflexa muito tardiamente ${ }^{27}$.

O ponto de partida deste pensamento é a própria pergunta metafísica ${ }^{28}: 0$ sujeito, quando reflete sobre si mesmo, se descobre como alguém que "necessariamente pergunta": o ser humano pergunta e não só pergunta por isto ou aquilo, mas quer em última instância saber o que é tudo em sua unidade, na qual tudo de certo modo já lhe é dado. Na pergunta pela totalidade do ser, o ser humano estabelece uma relação explícita com o ser e, com isto, com todos os entes, e o específico da filosofia é conhecer os entes no horizonte do ser: em linguagem heideggeriana podemos dizer que não são estruturas ônticas (relativas aos entes), mas ontológicas (relativas ao ser em seu sentido) que constituem o objeto específico da filosofia: ela é explicitação da "compreensão do ser" que caracteriza o ser humano enquanto ser humano, que é co-presente implicitamente no conhecimento de qualquer ente como sua condição de possibilidade. A compreensão do ser é o horizonte a partir de onde qualquer pergunta filosófica deve ser tratada, pois toda e qualquer pergunta só é inteligível no horizonte desta pergunta originária.

A pergunta pelo ser do ente é para Rahner algo último e irredutível, aquele fato que se recusa absolutamente a ser substituído por um outro fato, uma vez que todo questionar a pergunta é uma nova forma de perguntar. Deste modo, a pergunta é, por ora, a única necessidade a que o ser humano está vinculado: necessidade porque ela está co-contida em qualquer sentença da linguagem humana, já que toda afirmação humana sobre um ente determinado se efetiva no horizonte de um saber prévio, implícito, do ser enquanto tal, ou seja, um saber implícito sobre o ser é condição de possi-

${ }^{26}$ Cf. M.A. DE OLIVEIRA, Filosofia Transcendental e Religião, op. cit., p. 125.

${ }^{27}$ Cf. K. RAHNER, op. cit., vol. IX, p. 97.

${ }^{28}$ A respeito da comparação com o ponto de partida de J. Maréchal e as questões teóricas ligadas a esta postura cf. H. HOLZ, op. cit., p. 71ss. 
bilidade de qualquer conhecimento sobre um determinado ente. Isto já determina a direção da pesquisa filosófica: não só a filosofia leva adiante o perguntar por tudo que caracteriza o ser humano, mas ela pergunta pela própria possibilidade de perguntar.

Neste sentido, como diz Rahner, a filosofia não pergunta propriamente por coisas novas, mas é o conhecimento, metodicamente reflexo, conceitualmente articulado, daquilo que já sempre implicitamente conhecemos ${ }^{29}$, ou seja, metafísica enquanto "ciência" só existe aí onde o já sempre conhecido é desenvolvido por meio de um trabalho conceitual sistemático e rigoroso através do qual o ser humano procura elevar ao nível da compreensão conceitual aquela metafísica que ele já sempre é. Assim, a metafísica nada mais é do que a compreensão esclarecida, reflexa e metódica daquela précompreensão do ser que o ser humano é enquanto ser humano ${ }^{30}$ : o ser é para a metafísica o donde e o para onde, o começo e o fim de toda e qualquer pergunta ${ }^{31}$. Desta forma, filosofia enquanto metafísica é reflexão transcendental, ou seja, reflexão sobre os pressupostos necessários no próprio sujeito ${ }^{32}$ de nosso conhecimento do mundo ou, na linguagem de Rahner, tematização do que necessariamente co-afirmamos em nossas afirmações sobre os objetos do mundo e de todo e qualquer conhecimento e ação. Metafísica ${ }^{33}$ é, então, o conhecimento reflexo do que é necessariamente coposto no conhecimento humano, explicitação dos momentos que estão com necessidade contidos no exercício originário do conhecimento (pensamento) e da ação (vontade) humanos enquanto tais como sua condição de possibilidade $^{34}$.

Ora, o ser humano pergunta em última instância pela totalidade do ser, pela realidade enquanto tal e o mundo da experiência imediata em que ele se situa é o donde desta pergunta metafísica o que significa dizer que Rahner se põe na mesma perspectiva de $\mathrm{Kant}^{35}$, embora não tenha desta perspectiva a mesma compreensão: é enquanto ser do mundo, isto é, espacial e temporal, que o ser humano existe enquanto pergunta pelo ser. Ele pergunta pela totalidade do ser, não como a soma de todos os entes em sua multiplicidade, mas enquanto algo que compete a cada ente enquanto ente. Isto faz vir à tona a diferença (ontológica na linguagem de Heidegger) entre "ser" e "ente": a pergunta do ser humano é o lugar da manifestação

${ }^{29}$ Cf. K. RAHNER, Hörer des Wortes, op. cit., p. 47.

${ }^{30}$ Cf. K. RAHNER, Geist in Welt: Zur Metaphysik der endlichen Erkenntnis nach Thomas von Aquin, München: Kösel, ${ }^{2} 1957$, p. 47.

${ }^{31}$ Cf. K. RAHNER, Hörer des Wortes, op. cit., p. 55.

${ }^{32}$ Cf. K. RAHNER, "Theologie und Anthropologie", in op. cit., vol. VIII, p. 44.

${ }^{33}$ Cf. K. RAHNER, Geist in Welt, op. cit., p. 47.

${ }^{34}$ Cf. K. RAHNER, Geist in Welt, op. cit., p. 390.

${ }^{35}$ Cf. M.A. DE OLIVEIRA, Para além da fragmentação: Pressupostos e objeções da racionalidade dialética contemporânea, São Paulo: Loyola, 2002, pp. 93-134. 
da "diferença ontológica". Sua metafísica é a metafísica de um ser do mundo e ela é possível porque o ser humano já sempre é metafísico em seu ser, ele é a realização originária da "diferença ontológica". O ser humano, como ser-no-mundo, como espírito no mundo, já se encontra sempre no mundo dos entes, que são os objetos de seu conhecimento e de sua ação, mas é capaz de retornar a si pela reflexão e de situar tudo o que encontra no mundo no horizonte do ser.

O objeto de uma reflexão transcendental são justamente a relação e o condicionamento recíprocos entre o sujeito cognoscente e o objeto conhecido, portanto, a relação e o condicionamento recíprocos entre a subjetividade transcendental apriórica e o objeto aposteriórico. Para Rahner isto sempre esteve presente na tradição, embora só na modernidade tenha-se tomado plena consciência do que isto significa ${ }^{36}$. Metafísica, para Rahner, enquanto pergunta transcendental é, então, tematização do saber não-expresso do ser presente em todas as atividades humanas como sua condição de possibilidade. Nesta perspectiva o ser humano é condição de possibilidade da metafísica. Então, sendo o ser humano essencialmente pergunta pelo ser, abertura absoluta ao ser enquanto tal, toda pergunta metafísica é também pergunta por aquele que compreende ser, portanto, sempre também pergunta por aquele que necessariamente pergunta pelo ser, é aberto ao ser, numa palavra, metafísica é sempre também uma antropologia transcendental, isto é, a metafísica só é possível enquanto análise do ser humano enquanto pergunta pelo ser.

A pergunta pelo ser e a pergunta pelo ser humano que necessariamente pergunta pelo ser constituem uma unidade originária ${ }^{37}$. O "mútuo pertencer" entre ser e homem exprime-se epistemologicamente no mútuo pertencer de metafísica e antropologia. A pergunta metafísica articula-se, então, enquanto pergunta pelas condições de possibilidade da pergunta pelo ser que caracteriza o ser humano, ou seja, ela é o desdobramento transcendental da pergunta originária do ser humano, o que significa dizer que a metafísica é "antropologicamente mediada". A pergunta pelo ser do ser humano não é simplesmente uma pergunta por um campo regional da realidade, por um tema particular, mas tem a ver com a pergunta pela totalidade da realidade que constitui o núcleo da metafísica e nisto precisamente se revela a reviravolta transcendental da metafísica clássica.

Para conhecer qualquer ente determinado que ele encontra no mundo, o ser humano já se situa sempre na totalidade do ser; então, ele afirma com

${ }^{36}$ Para Rahner, neste sentido, a filosofia transcendental é a forma própria de toda e qualquer filosofia que, no entanto, só se tornou consciente a partir de Descartes e mais claramente ainda na filosofia de Kant e do Idealismo Alemão. Cf. K. RAHNER, op. cit., Vol. IX, p. 97.

${ }^{37}$ Cf. K. RAHNER, Hörer des Wortes, op. cit., p. 53. 
a necessidade com que ele sabe do ente singular, a questionabilidade do ser enquanto tal, uma vez que é impossível perguntar por algo completamente desconhecido, o que, por sua vez, implica afirmar a cognoscibilidade fundamental do ser, sua inteligibilidade originária. A pergunta filosófica é pergunta pelo ser enquanto tal, que necessariamente subjaz a toda atividade humana, o que pressupõe um certo conhecimento anterior do ser, pois sem este saber prévio, a pergunta pelo ser seria impossível ${ }^{38}$. Com isto já se tematizou uma determinação fundamental do ser enquanto tal: ser é conhecer e poder ser conhecido, uma determinação em que duas outras estão contidas: 1) uma unidade originária entre ser e conhecer; 2) uma não fixação essencial do que significa $\operatorname{ser}^{39}$.

O ser humano não pode perguntar pela totalidade do ser sem afirmar uma certa cognoscibilidade apriórica do ser enquanto tal, uma vez que toda pergunta pressupõe um certo saber sobre o que é perguntado, portanto, o ser é em si mesmo inteligível. Ora, afirma Rahner, uma relação essencialmente necessária entre dois estados de coisa tem que, em última instância, radicar-se numa unidade originária de ambos. Numa palavra, há uma correlação entre ser e conhecimento, porque originariamente, em seu fundamento, eles são o mesmo, o conhecimento é a subjetividade do próprio $\operatorname{ser}^{40}$. É isto o que Rahner denomina "o ser junto a si" (Bei-sich-sein), a iluminabilidade (Gelichtetheit) do ser para si enquanto subjetividade ${ }^{41}$. O ser mesmo é ontológico, isto é, a unidade originária de ser e conhecer $(\log o s)$ de tal modo que qualquer unidade atual num conhecimento determinado de ser e conhecer é somente a potenciação daquela síntese transcendental que o ser é em si mesmo ${ }^{42}$, enquanto síntese originária de ser e logos (lógica). Neste sentido, um ente incompreensível em seu ser é um absurdo: ente e possível objeto de um conhecimento são a mesma coisa precisamente, porque o ser do ente é cognoscibilidade, portanto, a cognoscibilidade é uma determinação de todo e qualquer ente, na terminologia escolástica, uma determinação transcendental (omne ens est verum) ${ }^{43}$. Todo ente possui assim essencialmente uma ordenação a um possível conhecimento, é em princípio cognoscível, inteligível, já que ser e conhecer constituem uma unidade originária, ou seja, pertence à essência do ser uma relacionalidade cognoscitiva a si mesmo, o conhecimento é o serjunto-a-si do ser, o que Tomás de Aquino denomina reditio subjecti in seipsum ${ }^{44}$.

${ }^{38}$ Cf. K. RAHNER, Hörer des Wortes, op. cit., p. 55.

${ }^{39}$ Cf. K. RAHNER, Geist in Welt, op. cit., p. 81.

${ }^{40}$ Cf. K. RAHNER, Hörer des Wortes, op. cit., pp. 56-57.

${ }^{41}$ Cf. K. RAHNER, Hörer des Wortes, op. cit., p. 62.

${ }^{42}$ Cf. K. RAHNER, Geist in Welt, op. cit., p. 83.

${ }^{43}$ Cf. K. RAHNER, Hörer des Wortes, op. cit., p. 56.

${ }^{44}$ Cf. K. RAHNER, Hörer des Wortes, op. cit., p. 61. 
Se metafísica é a análise transcendental da pergunta pelo ser, sua primeira sentença é: ser e conhecer constituem uma unidade originária, portanto, ser é autopresença, auto-reflexividade, subjetividade, e o ser humano que pergunta pelo ser é "espírito", isto é, abertura para o ser enquanto tal, mas também, enquanto pergunta pelo ser, a diferença para com o ser. Aquele que pergunta não pode simplesmente identificar-se com o ser uma vez que a pergunta pressupõe uma distância verdadeira entre o que pergunta e o que é perguntado, mas também não pode estar totalmente fora do ser, possui, portanto, o ser de alguma forma, embora não em absoluta identidade. Com isto se revela que há graus na posse do ser, ou seja, a sentença fundamental da identidade de ser e conhecer é uma grandeza internamente variável o que significa dizer que o ser em seu conceito mais formal não é fixável e é neste sentido um conceito "análogo ${ }^{45}$ ": ele se efetiva de diferentes modos. Desta forma se manifesta também um novo aspecto do ser: o grau de autopresença, de subjetividade, depende da forma de como o ser compete a um ente, ou o contrário, o grau da "posse do ser" se revela no grau em que um ente é capaz de retornar a si, de refletir sobre si, de ser presente a si. Numa palavra, a "reflexividade" é o critério para a determinação do grau de ser.

A primeira conseqüência que daqui brota é sobre o ser do ser humano: se ele pergunta pelo ser é porque não é o ser enquanto tal, portanto não é o ente da absoluta posse do ser, mas é um ente que possui o ser num grau específico, numa palavra, ele é finito, espírito finito, e sua finitude revelase precisamente na necessidade de perguntar; porém um finito que é aberto por sua pergunta à totalidade do ser, portanto, é consciência transcendental e seu conhecimento é em primeiro lugar um conhecimento que recebe o outro de si, do mundo, ele é conhecimento sensível. A abertura absoluta ao ser enquanto tal é a constituição fundamental do ser humano: o ser humano é espírito e enquanto tal ele não é um simples objeto do mundo, mas "julga" todas as coisas e assim se distingue de todas elas como sujeito, ser-junto-a-si, capaz de reflexividade plena, o que ocorre no juízo na medida em que aquele que faz o juízo se capta a si mesmo como distanciado do que é julgado justamente enquanto se compreende como sujeito deste juízo, portanto, se capta em sua subjetividade. E porque o ser humano sempre pensa através de juízos, ocorre sempre este retorno a si em seu pensamento. Ora, se o ser humano é aquele ente que é capaz de um retorno completo a si, isto faz surgir a pergunta a respeito do fundamento último da possibilidade do ser humano se distanciar enquanto sujeito das coisas que ele julga no conhecimento e com as quais ele tem que lidar em seu agir livre. Qual é a condição apriórica, transcendental, da subjetividade?

${ }^{45}$ Cf. A respeito da problemática da analogia do pensamento de K. Rahner: L.B. PUNTEL, Analogie und Geschichtlichkeit: Philosphiegeschichtlich-kritischer Versuch über das Grundproblem der Metaphysik, Freiburg / Basel / Wien: Herder, 1969, pp. 81-93. 
O pensamento humano se efetiva, tanto no conhecimento como na ação, em juízos; em qualquer "juízo" é afirmado um ente enquanto desta ou daquela espécie. A captação de um ente singular, enquanto ente de uma determinada espécie, nada mais é do que conceituar um singular, subordinar o singular a um conceito universal, levar o singular dado pela sensibilidade ao conceito. Justamente enquanto o ser humano, como cognoscente conceitual, sabe algo de algo, ele se distingue deste objeto e se capta como sujeito. Portanto, o fundamento da possibilidade da subjetividade é o mesmo que torna possível que o singular seja captado em conceitos. Na filosofia de Tomás de Aquino, diz Rahner ${ }^{46}$, a palavra básica para exprimir esta problemática é "abstração", o que significa dizer que a pergunta pela condição de possibilidade da subjetividade se determina agora enquanto pergunta pela condição de possibilidade da abstração enquanto consecução do conceito universal que é um "que" de um possível algo, um algo sabido sintetizável com um possível subjectum. Esta síntese concretizante se funda na síntese afirmativa que ocorre no juízo. A condição de possibilidade de ambas as sínteses está na possibilidade de conhecer o intuído sensivelmente como limitado ${ }^{47}$.

Abstrair significa separar, arrancar. Então, no conhecimento, abstração é a separação da "quididade" (Washeit), dada na sensibilidade, do singular em que ela é concretamente efetivada e com isto é conhecimento do caráter ilimitado da quididade dada no singular, no sentido de que ela é captada como possível determinação de outros singulares. A pergunta que se põe agora é pela condição transcendental de possibilidade da abstração, portanto, por uma condição $a$ priori no sujeito. Ora, a limitação da quididade efetivada num singular é captada na medida em que o ato, que capta este singular sensível dado, a priori já se situa em relação a esta captação para além deste singular na direção de "mais" do que este singular". Este "mais" não pode ser um objeto singular da mesma espécie do que foi abstraído, porque então voltaria a mesma pergunta. Assim, este "mais" só pode ser o ser enquanto horizonte e fundamento de todo conhecimento de objeto, de tal modo que todo conhecimento objetivo efetiva-se através da "antecipação" do ser enquanto seu horizonte último. O ser é fundamento das muitas possíveis quididades e com isto se mostra como ilimitado e as quididades como suas limitações: elas são, como diz Rahner, expressão da limitação do ser que em si não tem limites. As quididades não estão aí isoladas umas das outras, mas enquanto limitações do ser estão todas re-

${ }^{46}$ Cf. K. RAHNER, Hörer des Wortes, op. cit., p. 76.

${ }^{47}$ Cf. L.B. PUNTEL, op. cit., p. 89.

${ }^{48}$ Quando nos compreendemos a nós mesmos como limitados, o que, aliás, somos de forma radical, diz Rahner, já ultrapassamos nossos limites. Cf. K. RAHNER, op. cit., vol. IX, p. 167. Esta formulação é muito cara a Hegel. Cf. G.W.F. HEGEL, Enzyklopädie der philosophischen Wissenschaften im Grundriss, ed. por F. Nicolin / O. Pöggler, Hamburg: Felix Meiner, 1959, § 60, p. 84. 
feridas a ele e conseqüentemente entre si. O ser nesta perspectiva não é o conceito mais vazio, mas, ao contrário, é o conceito mais pleno, portanto, o fundamento dos conceitos mais pobres que são as quididades ${ }^{49}$. Por esta razão, em cada conhecimento, o ser humano capta algo não simplesmente como isolado em seu ser "este", mas a partir da totalidade de todos os objetos possíveis. Nesta perspectiva, a antecipação emerge como condição de possibilidade do conceito universal, da abstração, da objetivação e, conseqüentemente, da subjetivação, pois é através dela que um objeto singular é posto no horizonte do ideal absoluto do conhecimento. A antecipação é precisamente a abertura consciente deste horizonte e enquanto é condição de possibilidade de todo e qualquer conhecimento de objetos.

Uma pergunta fundamental faz prosseguir a análise: para onde vai a antecipação? Para onde transcende o conhecimento antecipador do ser humano na captação de um objeto singular? Qual é a abrangência do horizonte em que é situado o dado da sensibilidade? O conhecimento humano conhece o singular no horizonte do ser enquanto tal, ou seja, no todo de todos os possíveis objetos de conhecimento. Que é este todo? Que é a totalidade absoluta de todos os possíveis objetos? Esta transcendência do espírito humano não pode ser transcendência para o nada que não explicaria o conhecimento dos entes que o ser humano tem no mundo, mas antes é a transcendência ao ser, o ilimitado, que justamente torna possível a captação da limitação e com isto a revelação da finitude do que é captado e a negação nela implicada. O sim para o em si mesmo ilimitado é que é condição de possibilidade da negação e não o contrário. É precisamente o caráter ilimitado do horizonte transcendental do conhecimento humano que mostra a partir de si a finitude de tudo aquilo que não pode preenchêlo, ou seja, é justamente, a "In-finitude" do ser, a que vai a antecipação do conhecimento humano, que descobre a "Finitude" de tudo que é dado imediatamente ao ser humano. Todo conhecimento humano se efetiva assim na antecipação ao ser enquanto tal em sua infinitude. Então, na medida em que julgar e agir livremente pertencem à essência do ser humano, pertence a ela também a antecipação ao ser enquanto tal em sua infinitude.

Ora, na medida em que esta antecipação é posta necessariamente, é coafirmado Deus em sua infinitude, ou seja, enquanto o ser da posse absoluta do ser. Esta antecipação não apresenta Deus ao espírito como seu objeto imediato uma vez que a antecipação, enquanto condição de possibilidade de todo conhecimento de objetos, não representa objetos em si mesma. Porém, nesta antecipação já é co-afirmada a existência de um ente de posse absoluta de ser, portanto, de Deus, enquanto condição necessária e já sempre efetivada de todo conhecimento e de toda ação humanos uma vez que

${ }^{49}$ Cf. K. RAHNER, Geist in Welt, op. cit., p. 172. 
na antecipação é co-afirmada atematicamente o fundamento de sua possibilidade. Daí porque temos de afirmar: a antecipação vai para Deus, ou seja, a afirmação da finitude real de um ente exige, enquanto sua condição de possibilidade, a existência de um esse absolutum, o que implicitamente já ocorre na antecipação ao ser enquanto tal. Isto significa dizer que o ser humano enquanto espírito é abertura fundamental a Deus, condição última de possibilidade de todo seu conhecimento e de sua ação no mundo.

O ser humano é espírito, isto é, ele vive sua vida num permanente alargarse na direção do absoluto, em abertura a Deus, ele é assim a abertura infinita do finito a Deus ${ }^{50}$. O ser é inteligível, é Logos, portanto, pode ser revelado na palavra. O ser humano é espírito, então ele possui um ouvido para qualquer palavra que vier do absoluto, numa palavra, o ser humano é aquele ente que em sua liberdade está diante do Deus de uma possível revelação. O ser humano, enquanto sujeito transcendental de seu conhecimento e de sua ação, na ilimitação de sua transcendentalidade, se compreende a si mesmo na medida em que pergunta como ser finito. Por esta razão, ele sabe que sua transcendentalidade ao ser enquanto tal, portanto, a Deus, é mediada pela experiência aposteriórica dos objetos do mundo sobre que o sujeito não é senhor. Portanto, o retorno do sujeito sobre si mesmo em sua transcendentalidade originária significa ao mesmo tempo a captação de sua orientação fundamental ao conhecimento aposteriórico e à história. É esse o espaço de uma possível revelação ${ }^{51}$ por ser o lugar próprio do espírito finito.

A teologia é a reflexão metódica e sistemática da auto-revelação e autodoação gratificante de Deus ao ser humano captada e aceita na fé ${ }^{52}$. Enquanto atividade cognoscitiva humana tem como sua condição de possibilidade as condições necessárias de todo e qualquer conhecimento humano, numa palavra, está subordinada como qualquer conhecimento humano à estrutura apriórica de suas condições de possibilidade ${ }^{53}$ : o ser humano que faz teologia possui sempre, enquanto ser humano, "uma compreensão atemática de si e da totalidade do ser", transcendental e historicamente, que em última análise se explicita como abertura absoluta a Deus. Sendo assim, a teologia que verdadeiramente reflete, pensa e pretende ser

${ }^{50}$ Cf. K. RAHNER, Hörer des Wortes, op. cit., p. 86.

${ }^{51}$ Cf. K. RAHNER, op. cit., vol. IX, p. 99.

${ }^{52}$ Cf. K. RAHNER, Theologie, op. cit., pp. 861-862.

${ }^{53}$ L. B. Puntel fala do caráter regressivo do conhecimento teológico. Cf. L.B. PUNTEL, A teologia cristã, op. cit., p. 377: "Por sua vez, a teologia cristã é guiada por uma perspectiva regressiva no seguinte sentido: ela parte do Deus por assim dizer 'concretíssimo' ou 'absolutamente determinado', feito manifesto pela sua revelação na história: o Deus Trino, revelado em sua ação livre com respeito à humanidade. A teologia articula teoricamente este Deus supremamente 'determinado' 'regredindo' para todos os níveis pressupostos, ou, para usar a terminologia kantiana, para as condições de possibilidade da admissão de um tal Deus". 
algo mais do que um simples relato da história da salvação, tematiza uma filosofia como seu momento interno ${ }^{54}$, isto é, explicita a filosofia, enquanto reflexão transcendental sobre as condições de possibilidade de seu próprio conhecimento o que enquanto tal já é sempre um momento interno de seu trabalho.

Manfredo Araújo de Oliveira, é Mestre em Teologia pela Pontifícia Universidade Gregoriana de Roma, Doutor em Filosofia pela Universidade Ludwig-Maximilian de Munique na Alemanha. Professor Titular de Filosofia na Universidade Federal do Ceará e Professor visitante no curso de Mestrado-Doutorado em Filosofia da PUC do Rio Grande do Sul (Porto Alegre) e do CESEP (São Paulo). Dentre suas publicações mais recentes, destacam-se: A reviravolta lingüístico-pragmática na filosofia contemporânea, Loyola: São Paulo, 1996, (2ª ed. 2001); Diálogos entre Razão e Fé, Paulinas: São Paulo, 2000; Correntes Fundamentais da Ética Contemporânea (Org.), Vozes: Petrópolis, 2000 (2 $2^{\text {a }}$ ed. 2001); Desafios éticos da globalização, Paulinas: São Paulo, 2001,(2a ed. 2002); Para além da fragmentação, Loyola: São Paulo, 2002.

Endereço: R. Catão Mamede, 218/603

60140-110 Fortaleza - CE

e-mail: manfredo.oliveira@uol.com.br

${ }^{54}$ Cf. K. RAHNER, op. cit., vol.IX, p. 96. 